\title{
EXPERIMENTAL INVESTIGATION OF MINIMUM QUANTITY \\ LUBRICATION ON TOOL WEAR IN ALUMINUM ALLOY 6061-T6 USING DIFFERENT CUTTING TOOLS
}

\author{
M. Puvanesan ${ }^{1}$, M.M. Rahman ${ }^{1 *}$, M.S. Najiha ${ }^{1}$ and K. Kadirgama ${ }^{1}$ \\ ${ }^{1}$ Faculty of Mechanical Engineering, Universiti Malaysia Pahang \\ 26600 Pekan, Kuantan, Pahang, Malaysia \\ *Email: mustafizur@ump.edu.my \\ Phone: +6094246239; Fax: +6094246222
}

\begin{abstract}
In manufacturing, a great challenge is currently being faced in the competitive marketing place due to the manufacturing environment, low costs, the aim to achieve high rates of productivity and also the demand for high quality from customers. Aluminum alloys are being competitively used in current industries, especially in the automotive and aeronautics sector. This study is for experimental investigation of minimum quantity lubricant (MQL) for the end milling machining characteristics regarding tool wear during the machining of aluminum alloy 6061-T6. Process parameters including the cutting speed, depth of cut and feed rate are selected for study to develop a model of process optimization based on the response surface method. This experiment was conducted based on the central composite design method. Three types of tools are used in this experiment, namely, high speed steel, coated and uncoated carbide tools. The encouraging results include a significant reduction in the tool wear rate with MQL mainly through the reduction in the cutting zone temperature and a favorable change in the chip-tool and work-tool interaction. It is concluded that the MQL technique leads to economic benefits in terms of reduced lubricant costs and better machinability.
\end{abstract}

Keywords: Minimum quantity lubrication; aluminum alloy; machining; tool wear.

\section{INTRODUCTION}

Aluminum alloys are trending materials for machining in the current world (Fuh \& Chang, 1997; Najiha, Rahman, Kamal, Yusoff, \& Kadirgama, 2012; Najiha, Rahman, \& Yusoff, 2013; Razak, Rahman, \& Kadirgama, 2012) and are well known for application in the aerospace industries, especially the 2000 series aluminum alloys with high copper content (Fontalvo, Humer, Mitterer, Sammt, \& Schemmel, 2006). The aluminum alloy 6061-T6 is one of the popular materials used in fabricating thermally stable, high strength and lightweight nanostructure material through large strain deformation (Rao \& Shin, 2001). The demand for environmentally sustainable manufacturing is the primary driver for technology that can reduce the use of liquid coolant. However, the effectiveness of the cooling parameters cannot be determined simply by considering one function only. Metal cutting is a very complex system, and a small change in cutting conditions can have major consequences (Fuh \& Chang, 1997). The minimum quantity of lubrication (MQL) technique is becoming increasingly popular due to consideration of the safety of the environment. Moreover, the MQL technique not only leads to economic benefits by way of saving lubricant costs but also presents better machinability. The challenge of MQL usage is to dissipate the heat from the tool and workpiece in order to ensure dimensional integrity (Boswell \& Islam, 2012; Khan, 
Rahman, Kadirgama, Maleque, \& Ishak, 2011; Su, He, Li, \& Li, 2006; Yusoff, Mohamed Suffian, \& Taib, 2011). The economy of machining operations plays a key role in competitiveness in the market (Yazdi \& Khorram, 2010). The disadvantages of conventional metalworking fluids, such as disposal problems, health problems and economic factors, have led to the development of strategies to reduce the amount used in metalworking. The encouraging results include a significant reduction in the tool wear rate and surface roughness by MQL, mainly through reduction of the cutting zone temperature and favorable changes in the chip-tool and work-tool interaction. Identifying tool wear is important to prevent the surface of the material becoming damaged (Arokiadass, Palaniradja, \& Alagumoorthi, 2012; Razak et al., 2012). Tools are expected to reach their limit based on observation of the part surface quality and burr formation. (Boswell \& Islam, 2012) created certain criteria for tool failure, which were part surface, burr formation, flank wear greater than $0.3 \mathrm{~mm}$, or maximum notch wear of $1.0 \mathrm{~mm}$, and dramatic change in tool forces and cutting power. They examined the tool wear after machining each test sample by using a toolmaker microscope. The higher the material removal rate, the better it is, due to faster processing and to the repeated saving of the power consumed for cutting. But even though a higher material removal rate is good, the maximum removal rate could cause the tool to wear easily and also causes higher surface roughness. Therefore, an optimum result must be chosen which combines a lower surface roughness and higher material removal rate. The experimental study of different compositions of MQL lubricants will be reported in this paper. The effectiveness of the lubricants is determined in terms of their ability to protect the cutting tool during high speed machining of aluminum alloys, which are widely used in automotive industry. The main objective of this research is to quantitatively evaluate the ability of the lubricant's additive composition to reduce the tool wear. This is achieved by comparing the tool wear rate measured during the machining of aluminum alloy with the application of MQL.

\section{METHODOLOGY}

This research is performed to determine the machinability of aluminum alloy 6061-T6 under minimum quantity lubrication. The study of the aluminum alloy workpiece was conducted with different types of cutting tools. To achieve a good surface roughness, material removal rate and acceptable tool wear, the speed of machining was set to the optimum. Tables 1 and 2 show the chemical, mechanical and thermal properties of AA6061-T6. It is visible that the thermal conductivity is high, which reduces the chance of adhesion during machining. The dimension of the workpiece used in this study is $100 \times 100 \times 30 \mathrm{~mm}$. The four main parameters selected in this machining were the spindle speed, feed rate, depth of cut and MQL flow rate. With the use of three different tools made of TiN coated carbide, TiAlN coated carbide and uncoated carbide, the parameters were varied. Flooded machining was also done to compare the outcome with MQL machining. The design of the experiment was prepared using central composite design (CCD). Tables 3 and 4 show the design of experimental data used for the HSS tool, coated and uncoated tool by using flooded and MQL conditions.

Table 1. Physical properties of AA6061-T6.

\begin{tabular}{llllll}
\hline Component & $\mathrm{Si}$ & $\mathrm{Mn}$ & $\mathrm{Mg}$ & $\mathrm{Ti}$ & $\mathrm{Zn}$ \\
\hline Weight $(\%)$ & $0.4-0.8$ & Max 0.15 & $0.8-1.2$ & Max 0.15 & Max 0.25 \\
\hline
\end{tabular}


Before machining, the workpiece was clamped tightly onto the vice. It was then cleaned on the surface with a soft cloth to prevent damage during cutting. It was tightly clamped at least $10 \mathrm{~mm}$ on top of a parallel bar and its initial position was marked with a marker on the vice so that the next workpieces did not need to be set its origin. Figure 1 shows the CNC end milling machine HAAS VF-6 used to complete the cuts with coated and uncoated carbide inserts. The experiment was conducted based on the design of experiments that was selected by using CCD. The minimum quantity lubrication used in this experiment was UNIST 2210, which is a commercial non-toxic type, vegetable oil-based cutting fluid. Three nozzles were fixed on the machine spindle and were set 30 degrees approximately from horizontal. The nozzles were set 120 degrees apart so that they could cover the whole machining area. Figure 2 shows the MQL system with the coolant used and the nozzle configuration. After machining, every tool was then examined under a scanning electron microscope to check the tool wear.

Table 2. Mechanical and thermal properties of AA6061-T6.

\begin{tabular}{lcc}
\hline \multicolumn{1}{c}{ Properties } & Value & Unit \\
\hline Hardness, Brinell & 95 & - \\
Hardness, Knoop & 120 & - \\
Hardness, Rockwell A & 40 & - \\
Hardness, Rockwell B & 60 & - \\
Hardness, Vickers & 107 & - \\
Ultimate tensile strength & 310 & $\mathrm{MPa}$ \\
Tensile yield strength & 276 & $\mathrm{MPa}$ \\
Elongation at break & 12 & $\%$ \\
Elongation at break & 17 & $\%$ \\
Modulus of elasticity & 68.9 & $\mathrm{GPa}$ \\
Density & 2.7 & $\mathrm{~g} / \mathrm{cc}$ \\
Specific heat capacity & 0.896 & $\mathrm{~J} / \mathrm{g}-{ }^{\circ} \mathrm{C}$ \\
Thermal conductivity & 167 & $\mathrm{~W} / \mathrm{m}-\mathrm{K}$ \\
Melting point & 652 & ${ }^{\circ} \mathrm{C}$ \\
\hline
\end{tabular}

Table 3. DOE matrix for flooded cooling with uncoated and coated carbide inserts

\begin{tabular}{cccc}
\hline Levels & Speed $(\mathrm{rpm})$ & Feed rate $(\mathrm{mm} / \mathrm{min})$ & Depth of cut $(\mathrm{mm})$ \\
\hline-2 & 5237 & 279 & 0.367 \\
-1 & 5300 & 318 & 1.0 \\
0 & 5400 & 379 & 2.0 \\
1 & 5500 & 440 & 3.0 \\
2 & 5563 & 479 & 3.633 \\
\hline
\end{tabular}

Table 4. Design of experiment matrix for MQL with uncoated and coated carbide inserts

\begin{tabular}{ccccc}
\hline Levels & $\begin{array}{c}\text { Speed } \\
(\mathrm{rpm})\end{array}$ & $\begin{array}{c}\text { Feed rate } \\
(\mathrm{mm} / \mathrm{min})\end{array}$ & $\begin{array}{c}\text { Depth of cut } \\
(\mathrm{mm})\end{array}$ & $\begin{array}{c}\text { Flow rate } \\
(\mathrm{ml} / \mathrm{min} / \text { nozzle })\end{array}$ \\
\hline-2 & 5252 & 288 & 0.52 & 0.0130 \\
-1 & 5300 & 318 & 1.0 & 0.0160 \\
0 & 5400 & 379 & 2.0 & 0.0220 \\
1 & 5500 & 440 & 3.0 & 0.0275 \\
2 & 5548 & 469 & 3.5 & 0.0300 \\
\hline
\end{tabular}




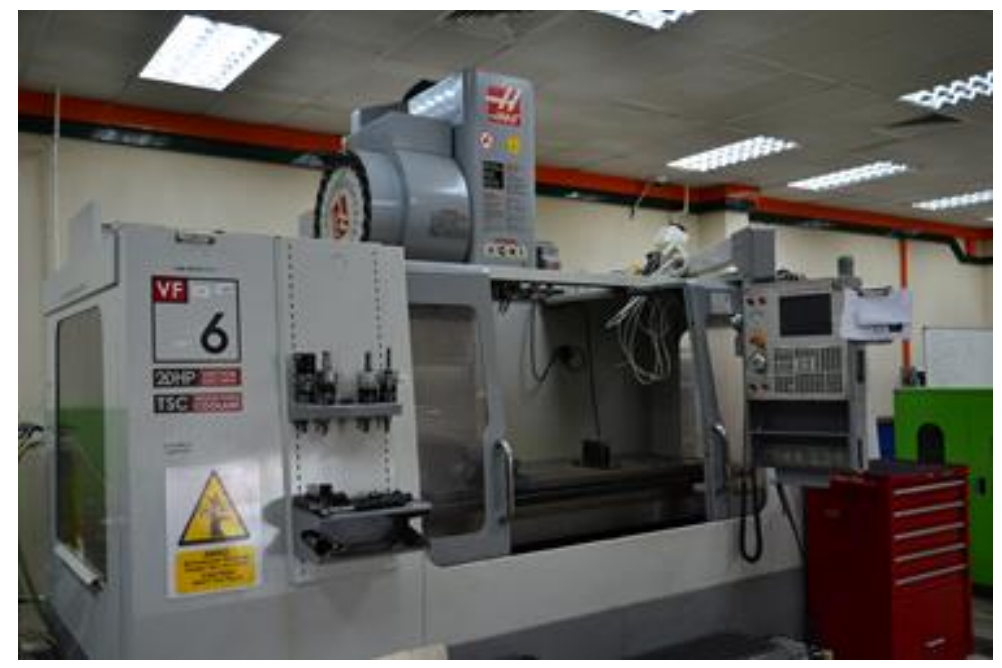

Figure 1. CNC end milling machine HAAS VF-6

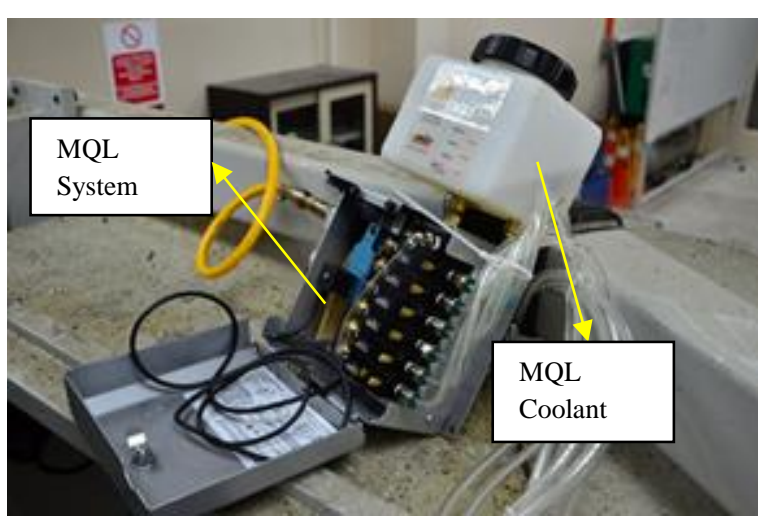

(a)

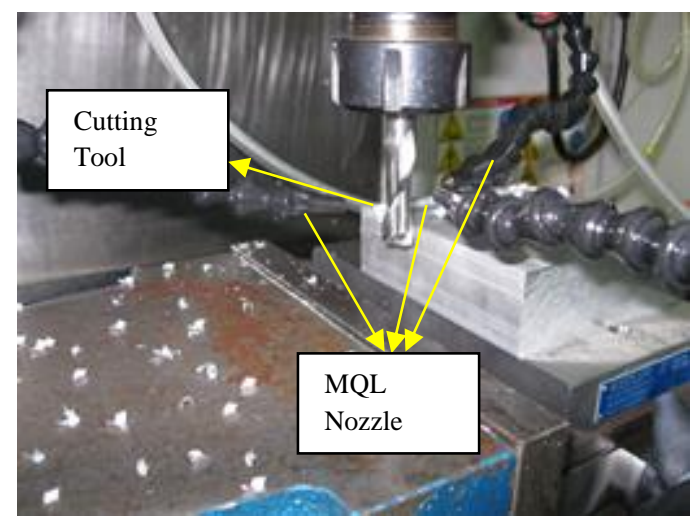

(b)

Figure 2. (a) MQL system and UNIST 2210 coolant; (b) configuration of nozzles

\section{RESULTS AND DISCUSSION}

Figure 3 shows the variation of tool wear on spindle speed for the MQL and flooded condition. It can be seen that the tool wear increases as the spindle speed increases. This is due to the increase in heat between the tool and the workpiece (Fontalvo et al., 2006). Moreover, the frictional force between the tool and workpiece causes it to create rubbing marks, which are also the beginning stage of flank wear. For coated carbide 2235 , the values of maximum tool wear are similar to each other and both show a generally increasing result. At the same time, coated carbide 1235 for MQL shows an obvious increase in tool wear as the spindle speed increases, but increase in the tool wear can hardly be seen in the flooded test. This could be because the feed rate was set to the minimum. Almost the same patterns are seen for uncoated carbide 4615, for both the MQL and flooded tests. Although there is a difference in tool wear values, all of these for both the flooded and MQL tests are considered to be in the safe range according to ISO 8688, that is, below $0.3 \mathrm{~mm}$ (Habeeb et al., 2010; Kadirgama \& Abou-El-Hossein, 2006; Kalidass, Palanisamy, \& Muthukumaran, 2012). Based on the 
graphs, it can be seen that coated carbide 2235 would be suitable for use under a high spindle speed as the increase in tool wear is very low and the maximum tool wear is below $0.055 \mathrm{~mm}$ compared to other tools.
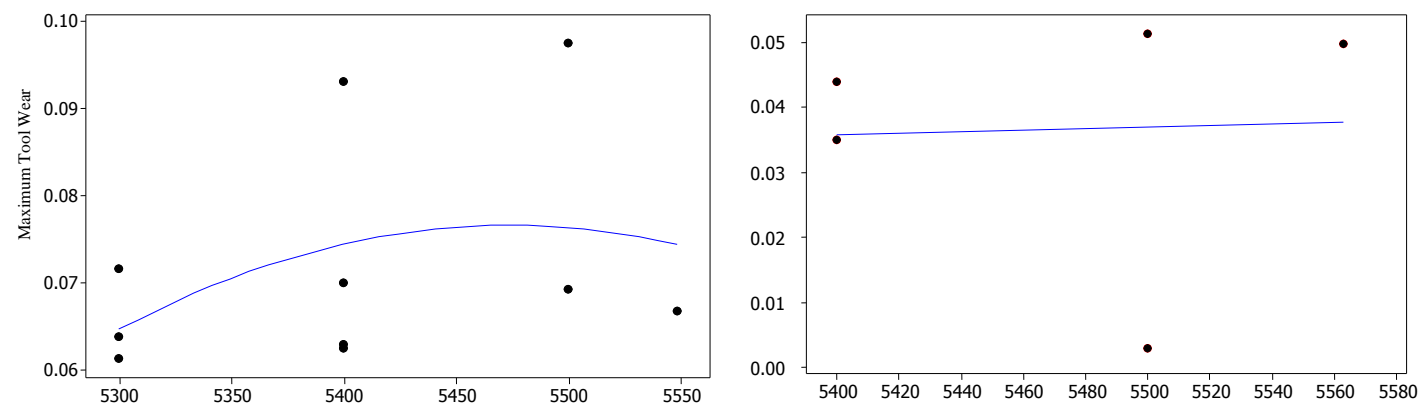

(i) Coated carbide 2235
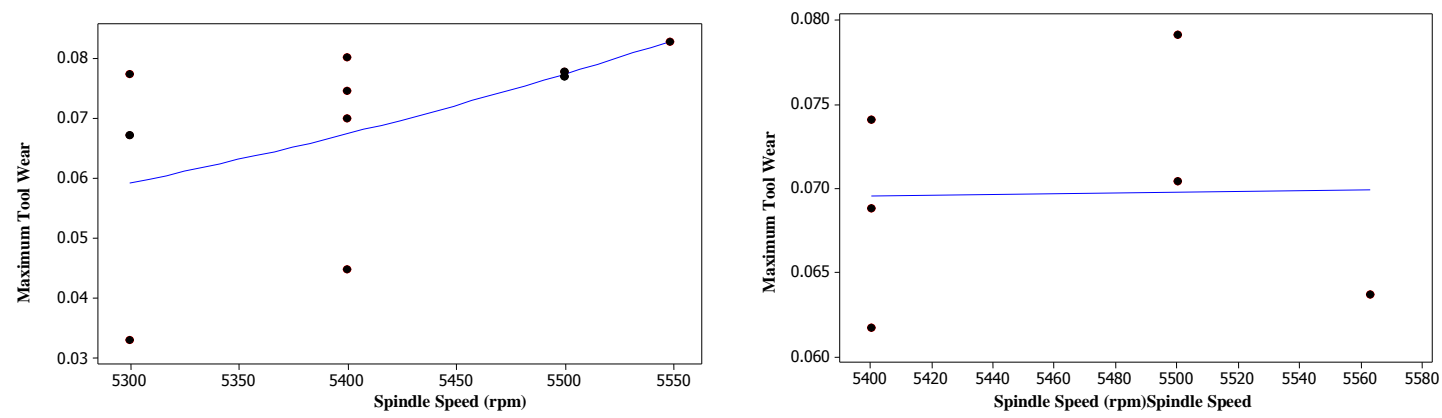

(ii) Coated carbide 1235
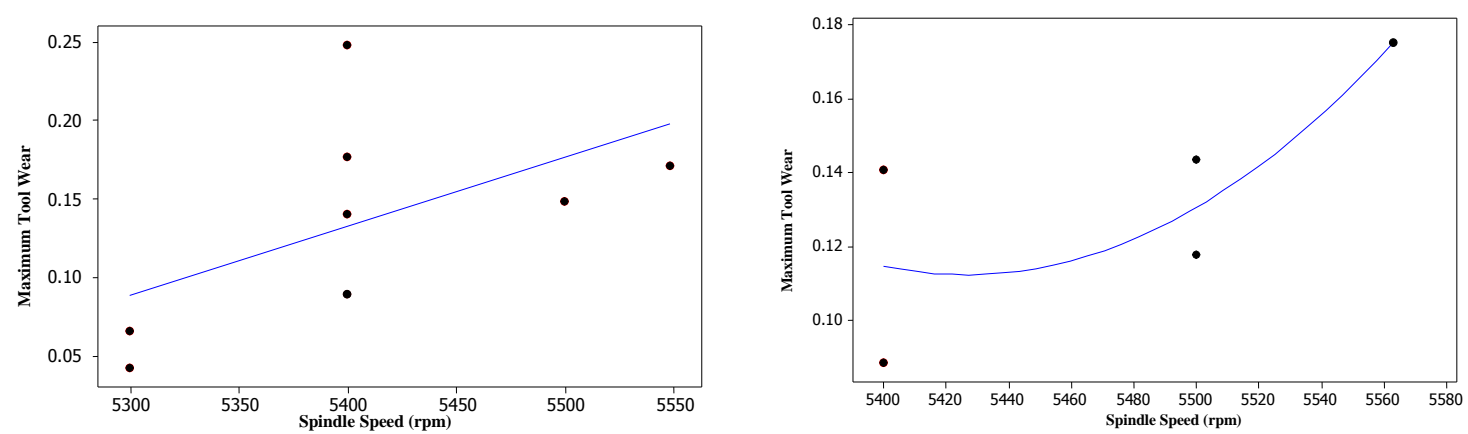

(iii) Uncoated carbide 4615

(a) MQL

(b) Flooded

Figure 3. Effects of tool wear on spindle speed for MQL and flooded conditions

Figure 4 shows the effect of tool wear on feed rate for the MQL and flooded cutting conditions. It can be seen that the tool wear decreases as the feed rate increases. The effect of the feed rate depends also on other factors, mainly spindle speed. This is because the feed rate and spindle speed involve movement which then decides the thermal barrier and also frictional forces between the tool and workpiece. For coated carbide 2235, the MQL and flooded conditions show a decrease in the tool wear. Meanwhile, coated carbide 1235 with MQL also shows a decrease in tool wear, but with 
the flooded condition shows an increase in tool wear as the feed rate increases. Flooded coated carbide 1235 shows an increase only until reaching $440 \mathrm{~mm} / \mathrm{min}$, after which the tool wear tends to reduce. At $440 \mathrm{~mm} / \mathrm{min}$, tool wear seems high due to the high spindle speed which was set at $5500 \mathrm{rpm}$. On the other hand, uncoated carbide 4615 shows a very similar result. For MQL, the graph increases and then reduces at a feed rate of 380 $\mathrm{mm} / \mathrm{min}$. This is due to the maximum spindle speed at that feed rate (Kadirgama, Noor, \& Rahman, 2012; Noor, Kadirgama, Habeeb, Rahman, \& Mohammad, 2010; Razak et al., 2012).
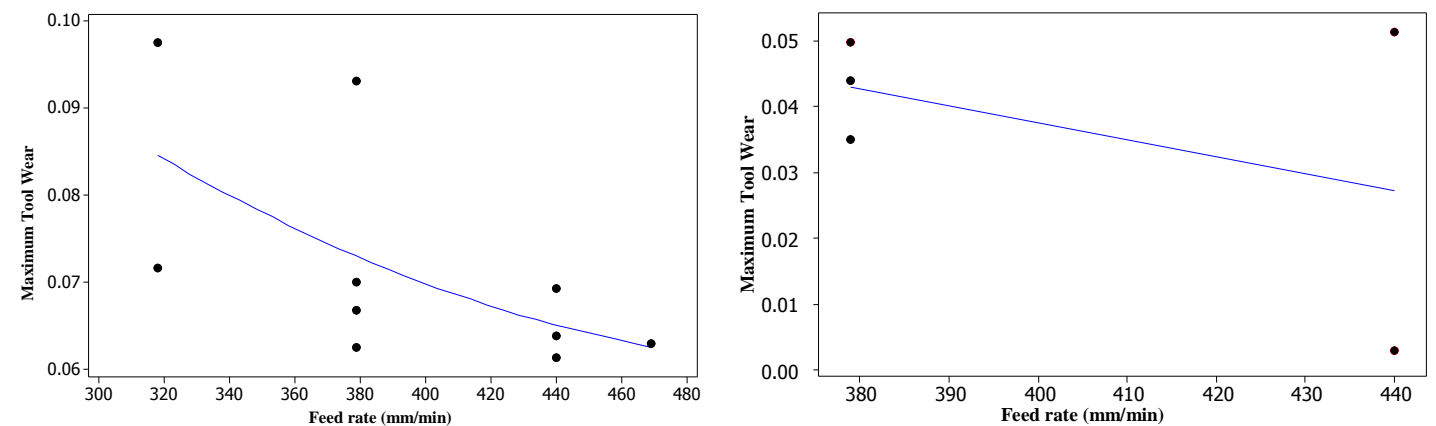

(i) Coated carbide 2235
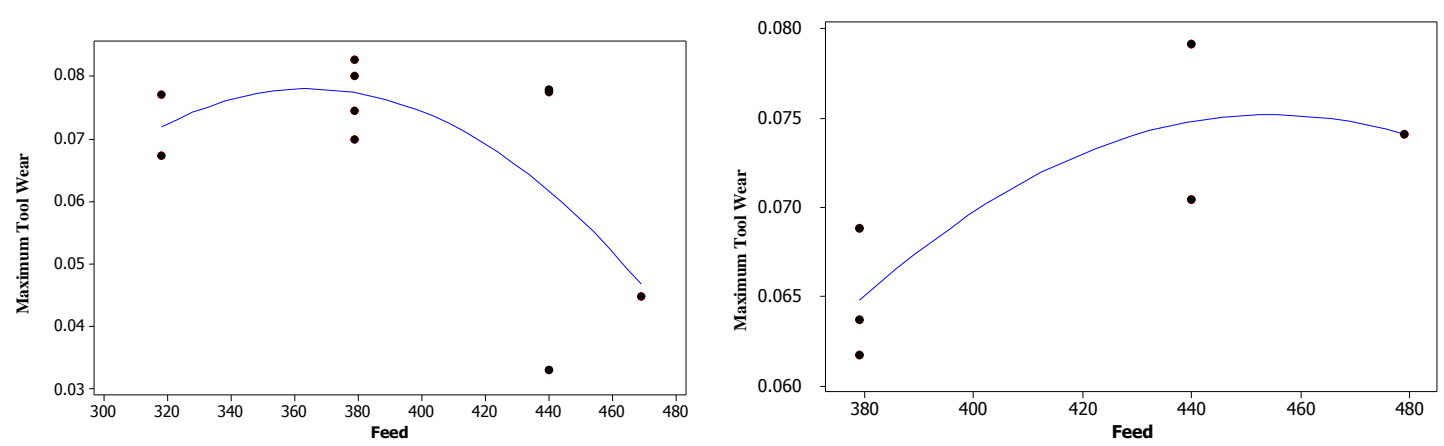

(ii) Coated carbide 1235
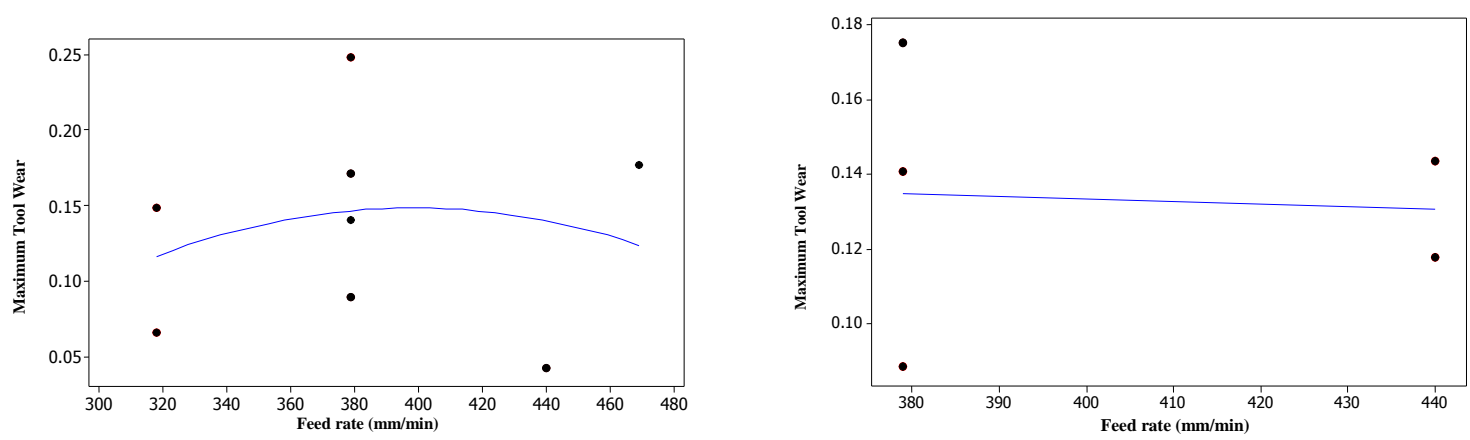

(iii) Uncoated carbide 4615

(a) MQL

(b) Flooded

Figure 4. Variation of tool wear against feed rate for MQL and flooded conditions 
Meanwhile, reducing trends were seen for flooded uncoated carbide 4615 because of the contact time between the tool and workpiece. When the feed rate was too low, the time taken for a cut was longer and thus increased the heat. This leads to damage to the tool. Therefore, using a high and optimum feed rate is recommended as it can reduce the tool wear and at the same time increase the material removal rate. In terms of MQL, coated carbide 2235 shows a good trend. Even though the maximum tool wear is higher than that of MQL of coated carbide 1235, the values are still below the acceptable value for tool wear.
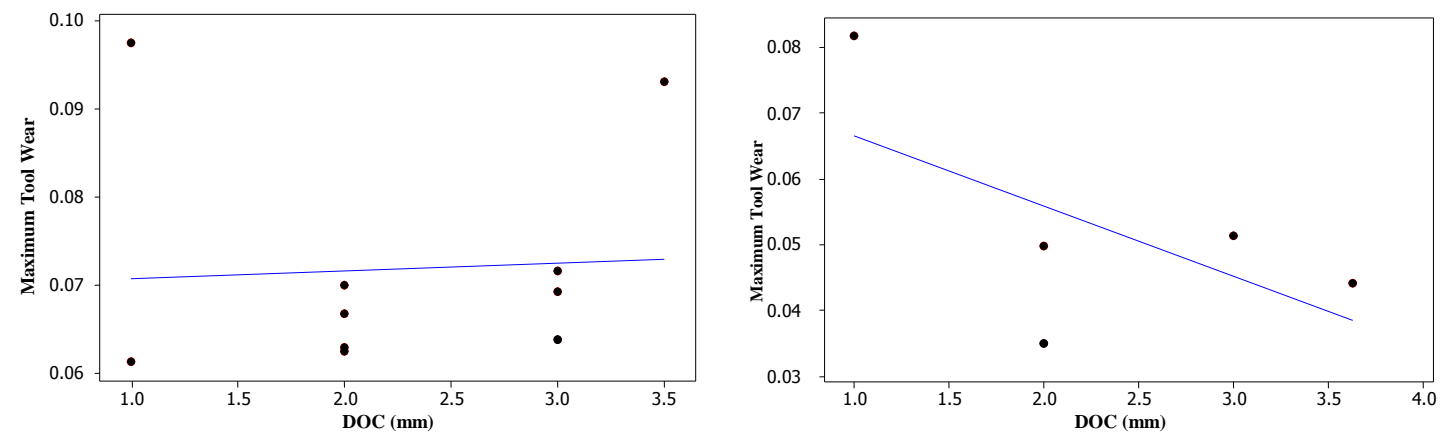

(i)Coated carbide 2235
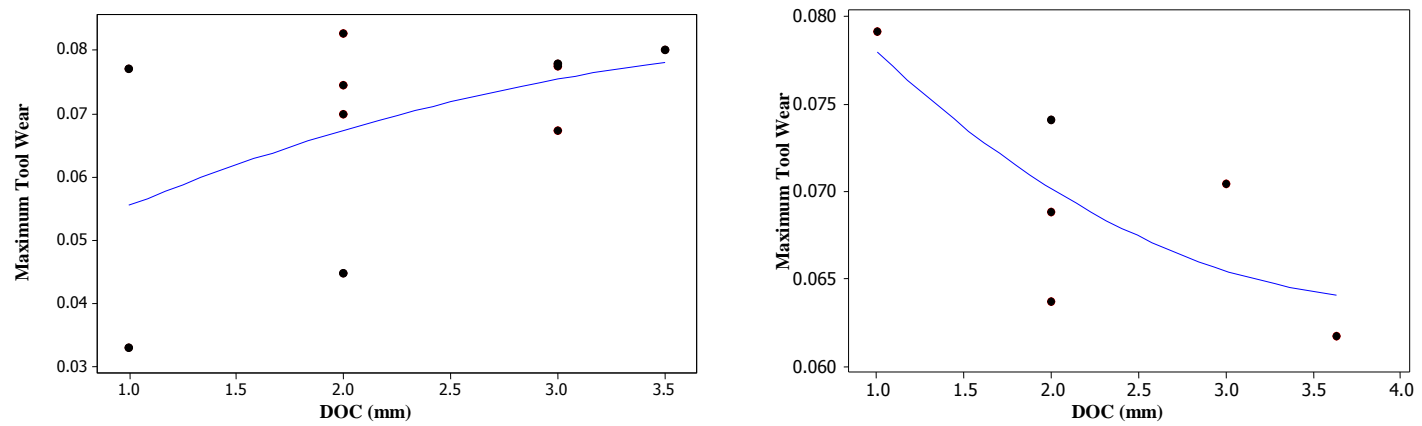

(ii) Coated carbide 1235
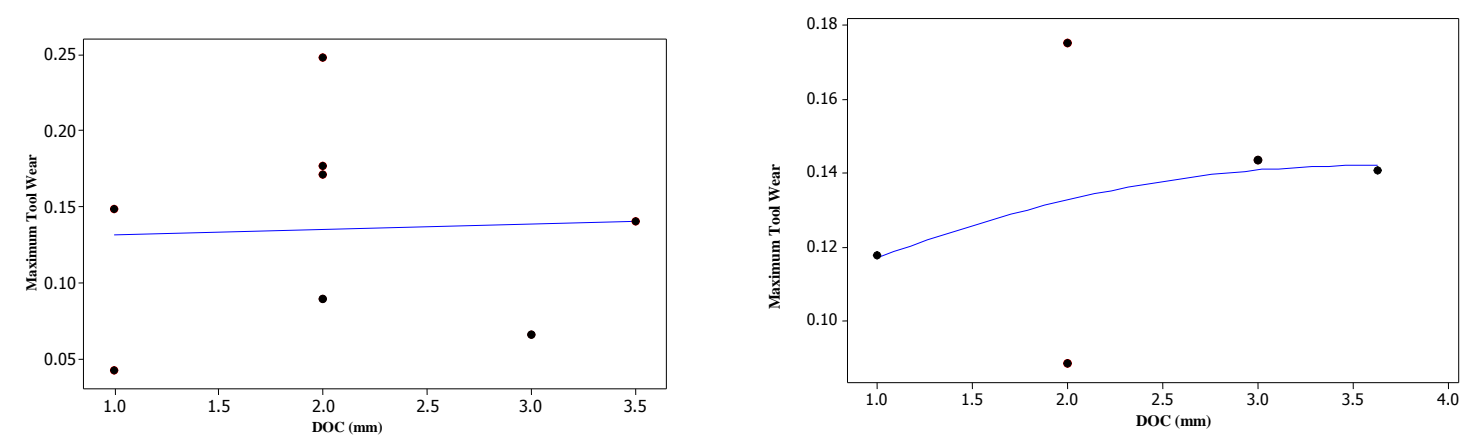

(iii) Uncoated carbide 4615

(a) MQL

(b) Flooded

Figure 5. Variation of tool wear on depth of cut for MQL and flooded condition

Figure 5 shows the effect of the depth of cut on tool wear for the MQL and flooded conditions. With increasing depth of cut, the tool wear decreases. This is because, with a deeper cut, the tool tends to have less chatter vibration, thus causing the propagation of tool wear to be in the steady region. Tool wear is usually related to 
vibration on tools during machining. For coated carbide 2235, the tool wear seems to be increasing at a much lower rate for MQL and it directly reduces in the flooded condition. Basically, all the results for MQL show a slight increase in tool wear. This could be due to the usage of minimum lubricant which occupies less of the space between the tool and workpiece during machining. This contrasts with the flooded condition which could cover the whole area between the tool and workpiece, thus reducing the frictional force and heat that can damage the tool. Coated carbide 4615 shows increasing tool wear against depth of cut due to the minimum feed rate and high spindle speed at $3.63 \mathrm{~mm}$ depth of cut. Coated carbide 2235 and 1235 when flooded show a similar trend of decreasing tool wear with increasing depth of cut (Kadirgama, Abou-El-Hossein, Noor, Sharma, \& Mohammad, 2011a, 2011b). Thus both of these tools could be selected for machining AA6061-T6. Meanwhile, coated carbide 2235 shows a lower tool wear value and a lower increase in the rate of tool wear compared to the other two tools.

Figure 6 shows the variation of tool wear on the MQL flow rate for different coated and uncoated carbide inserts. With more lubrication, the tool wear could be decreased. This is because the lubricant acts as a cooling agent and reduces the temperature and frictional forces between the inserts and tool (Su et al., 2006). Coated carbide 1235 shows a good result when using MQL. The tool wear decreases as the MQL flow rate increases and the tool wear shows the lowest value compared to the other two tools. The graph for coated carbide shows a slight increase in tool wear as the MQL flow rate increases. This could be affected by the low feed rate, high spindle speed and low depth of cut, which was selected at $0.0275 \mathrm{ml} / \mathrm{min}$. This causes high tool wear and thus causes the graph trend to be slightly increasing. Most of the tool wear values are in the acceptable region, which is below $0.3 \mathrm{~mm}$ (Noor, Kadirgama, Rahman, \& Maleque, 2011).

Figure 7 presents the characteristics of tool wear on different inserts for the MQL and flooded cutting conditions. It can be seen that the most common types of tool wear in this study are flank wear and the adhesive layer. Flank wear usually happens on the relief part of the insert and mainly occurs due to rubbing of the inserts and workpiece. Lubricants play an important role in ensuring that the friction force and resulting heat transfer are less, thus causing less flank wear to appear. However, the appearance of flank wear is similar in both cases. It could lead to reduction in the nose radius of the inserts when the amount of flank wear increases. This affects the surface roughness of the workpiece. An increase in the depth of cut affects the appearance of the adhesive layer due to increased workpiece surface contact with the inserts. High temperature and high force are the main reasons for adhesion (Kadirgama, Noor, Rahman, Sani, \& Abou-El-Hossein, 2010; Kalidass et al., 2012; Rahman Khan, Rahman, Kadirgama, \& Ismail, 2012)The adhesive layer on machined inserts can be reduced by using carbide coated inserts (Fontalvo et al., 2006). This study also shows that the adhesive layer on uncoated carbide can be seen frequently compared to coated carbides. In this study, two different types of coated carbide were used, namely titanium nitride (TiN) for coated carbide 1235 and titanium aluminum nitride (TiAlN) for coated carbide 2235. Damage such as edge fracture and notch wear could also be identified on the inserts. The damage can be more frequently seen in the microstructure when using flooded lubricants than with MQL. However, the amount of adhesive layer on flooded inserts is less compared to MQL. The MQL lubricants are formulated with two major groups of additives; anti-wear additives and extreme pressure additives. When such lubricants are applied to the cutting zone, protective layers are formed on the interacting 
surfaces of the workpiece and the cutting tool. These layers prevent direct contact between the tool and chip surfaces, and therefore reduce the friction forces and tool wear. In order to utilize MQL to its full potential, it is essential to select the appropriate lubricant composition for the particular work material and machining parameters.

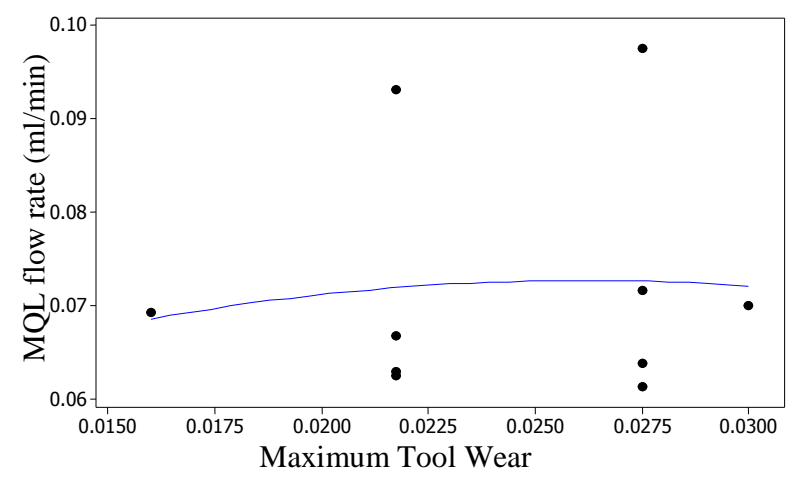

(i) Coated carbide 2235

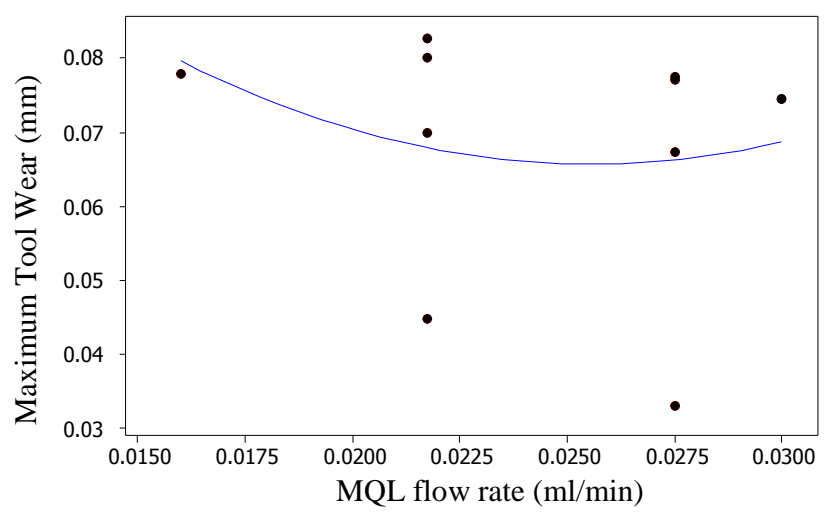

(ii) Coated carbide 1235

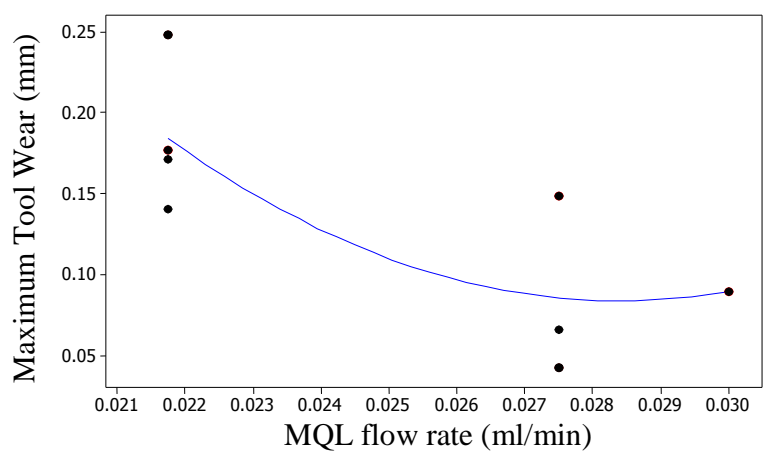

(iii) Uncoated carbide 4615

Figure 6. Variations of tool wear on MQL flow rate for different inserts 

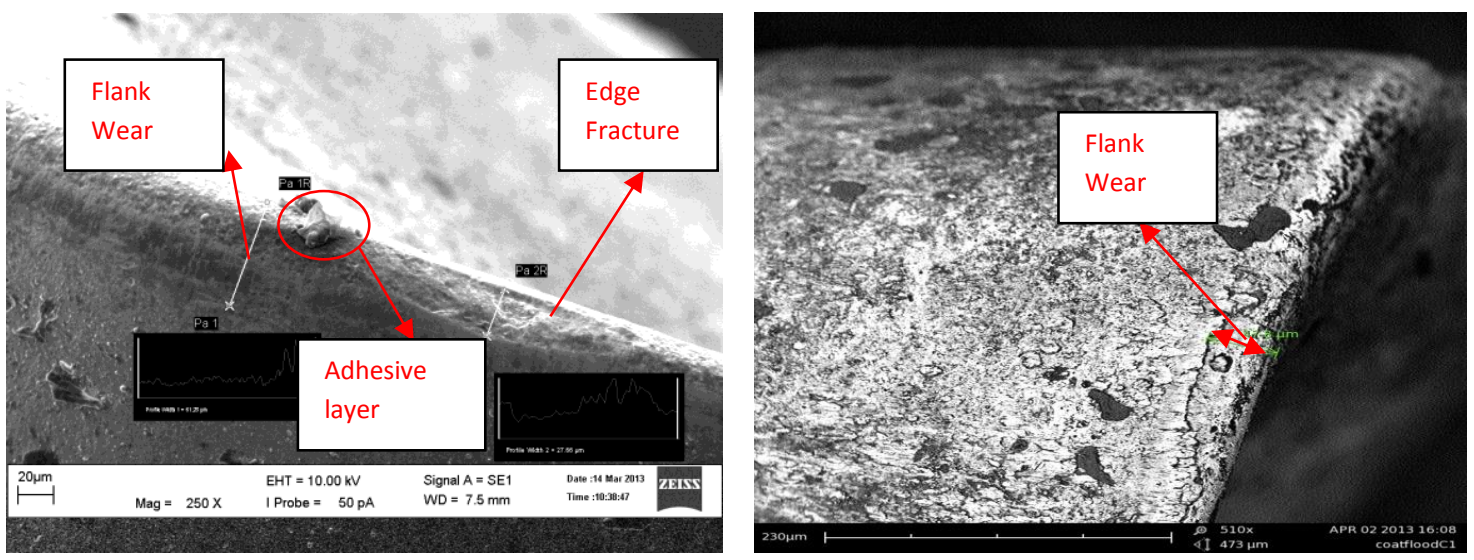

(i) Coated carbide 2235
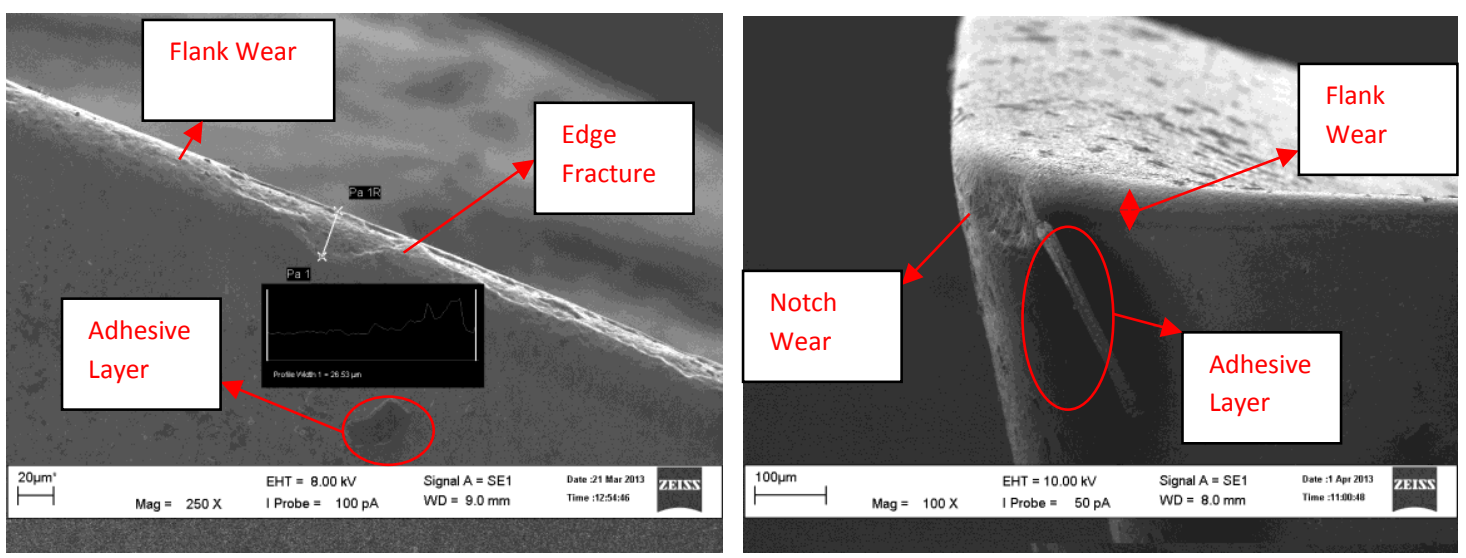

(ii) Coated carbide 1235
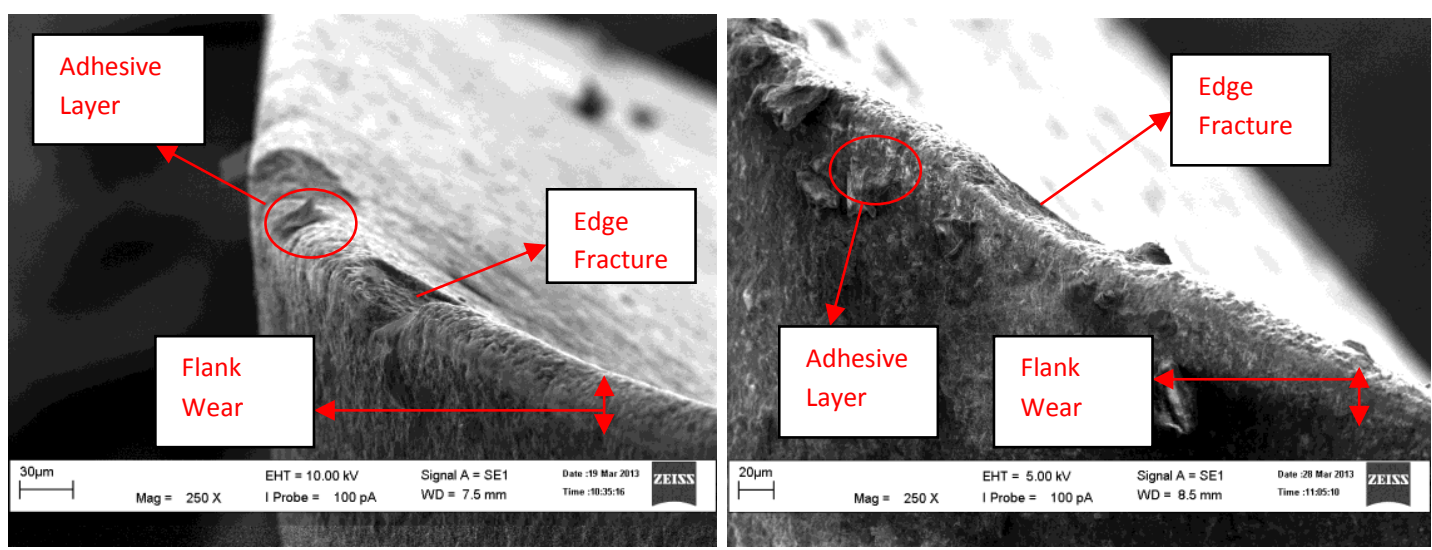

(iii) Uncoated carbide 4615

(a) MQL

(b) Flooded

Figure 7. Tool wear on different inserts for MQL and flooded conditions: (i) coated carbide 2235; (ii) coated carbide 1235; (iii) uncoated carbide 4615. 


\section{CONCLUSIONS}

Minimum quantity lubrication technology seems to be a suitable alternative for economically and environmentally compatible production. It combines the functionality of lubrication with an extremely low consumption of lubricant and has the potential to replace the metalworking fluids currently applied in machining operations. It is concluded that the cutting parameters and MQL flow rate play an important role in determining tool wear. Flooded and minimum quantity lubrication show similar results in terms of tool wear. The high value of spindle speed, and lower feed rate, depth of cut and lubrication caused severe tool wear. A higher spindle speed caused more severe flank wear propagation. In this study, cutting tool inserts were identified to have an adhesive layer that became easily attached to the inserts as the cutting temperature increased. MQL can be beneficial for machining of aluminum alloy as it can give a similar result in terms of tool wear to flooded lubricant. Even though the tool wear with MQL was slightly higher than that in the flooded condition, all the results were in an acceptable range. Coated carbide 2235 shows a good overall performance under different parameters. The results imply that the study can be used easily to forecast tool wear in response to cutting parameters.

\section{REFERENCES}

Arokiadass, R., Palaniradja, K., \& Alagumoorthi, N. (2012). Prediction and optimization of end milling process parameters of cast aluminium based mmc. Transactions of Nonferrous Metals Society of China, 22, 1568-1574.

Boswell, B., \& Islam, M. N. (2012). Feasibility study of adopting minimal quantities of lubrication for end milling aluminium. Paper presented at the Proceedings of the World Congress on Engineering.

Fontalvo, G. A., Humer, R., Mitterer, C., Sammt, K., \& Schemmel, I. (2006). Microstructural aspects determining the adhesive wear of tool steels. Wear, 260, 1028-1034.

Fuh, K. H., \& Chang, H. Y. (1997). An accuracy model for the peripheral milling of aluminum alloys using surface response design. Journal of Materials Processing Technology, 72, 42-47.

Habeeb, H. H., Kadirgama, K., Noor, M. M., Rahman, M. M., Mohammad, B., Bakar, R. A., \& Abouel Hossein, K. A. (2010). Machining of nickel alloy 242 with cubic boron nitride tools Journal of Applied Sciences, 10, 2322-2327.

Kadirgama, K., \& Abou-El-Hossein, K. A. (2006). Prediction of cutting force model by using neural network. Journal of Applied Sciences, 6(1), 31-34.

Kadirgama, K., Abou-El-Hossein, K. A., Noor, M. M., Sharma, K. V., \& Mohammad, B. (2011b). Tool life and wear mechanism when machining hastelloy C-22HS. Wear, 270(3-4), 258-268.

Kadirgama, K., Noor, M. M., \& Rahman, M. M. (2012). Optimization of surface roughness in end milling using potential support vector machine. Arabian Journal for Science and Engineering, 37(8), 2269-2275.

Kadirgama, K., Noor, M. M., Rahman, M. M., Sani, M. S. M., \& Abou-El-Hossein, K. A. (2010). Optimised tool life by partial swarm optimisation. International Journal of Material Forming, 3(SUPPL. 1), 479-482.

Kalidass, S., Palanisamy, P., \& Muthukumaran, V. (2012). Prediction of tool wear using regression and artificial neural network models in end milling of aisi 304 
austenitic stainless steel. International Journal of Engineering and Innovative Technology, 29-36.

Khan, M. A. R., Rahman, M. M., Kadirgama, K., Maleque, M. A., \& Ishak, M. (2011). Prediction of surface roughness of ti-6al-4v in electrical discharge machining: A regression model. Journal of Mechanical Engineering and Sciences, 1, 16-24.

Najiha, M. S., Rahman, M. M., Kamal, M., Yusoff, A. R., \& Kadirgama, K. (2012). Minimum quantity lubricant flow analysis in end milling processes: A computational fluid dynamics approach. Journal of Mechanical Engineering and Sciences, 3, 340-345.

Najiha, M. S., Rahman, M. M., \& Yusoff, A. R. (2013). Modeling of the end milling process for aluminum alloy aa6061t6 using hss tool. International Journal of Automotive and Mechanical Engineering, 8, 1140-1150.

Noor, M. M., Kadirgama, K., Habeeb, H. H., Rahman, M. M., \& Mohammad, B. (2010). Performance of carbide cutting tools when machining of nickel based alloy. International Journal of Material Forming, 3(SUPPL. 1), 475-478.

Noor, M. M., Kadirgama, K., Rahman, M. M., \& Maleque, M. A. (2011) Pattern recognition method to predict recycling strategy for electronic equipments. Advanced Materials Research, 264-265, 949-955.

Rahman Khan, M. A., Rahman, M. M., Kadirgama, K., \& Ismail, A. R. (2012). Mathematical model for wear rate of negative graphite electrode in electrical discharge machining on Ti-5A1-2.5Sn. Jurnal Teknologi (Sciences and Engineering), 59(SUPPL.2), 55-59.

Rao, B., \& Shin, Y. C. (2001). Analysis on high-speed face-milling of 7075-t6 aluminum using carbide and diamond cutters. . International Journal of Machine Tools and Manufacture, 41, 1763-1781.

Razak, N. H., Rahman, M. M., \& Kadirgama, K. (2012). Investigation of machined surface in end-milling operation of hastelloy c-2000 using uncoated-carbide insert. Advanced Science Letters, 13, 300-305.

Su, Y., He, N., Li, L., \& Li, X. L. (2006). An experimental investigation of effects of cooling/lubrication conditions on tool wear in high-speed end milling of Ti-6Al4V. Wear, 261, 760-766.

Yazdi, M. R. S., \& Khorram, A. (2010). Modeling and optimization of milling process by using rsm and ann methods. . International Journal of Engineering and Technology, 2(5), 474-480.

Yusoff, A. R., Mohamed Suffian, M. R. Z., \& Taib, M. Y. (2011). Literature review of optimization technique for chatter suppression in machining. Journal of Mechanical Engineering and Sciences, 1, 47-61. 